\title{
Zalecenia dietetyczne dotyczące spożywania jodu - w poszukiwaniu konsensusu między kardiologami a endokrynologami
}

\author{
lodine dietary recommendations - in search of a consensus \\ between cardiologists and endocrinologists
}

\author{
Beata Pyka ${ }^{1,2}$, Iwona Zieleń-Zynek² (D), Joanna Kowalska², Grzegorz Ziółkowski², \\ Bartosz Hudzik $^{2,3}$ (D), Mariusz Gąsior ${ }^{3}$ (D), Barbara Zubelewicz-Szkodzińska ${ }^{1,2}$ (D) \\ ${ }^{1}$ Oddział Endokrynologii Piekarskiego Centrum Medycznego w Piekarach Śląskich \\ ${ }^{2}$ Katedra Profilaktyki Chorób Metabolicznych Wydziału Zdrowia Publicznego w Bytomiu, \\ Śląski Uniwersytet Medyczny w Katowicach \\ ${ }^{3}$ III Katedra i Oddział Kliniczny Kardiologii Śląskiego Centrum Chorób Serca w Zabrzu, Wydział Lekarski \\ z Oddziałem Lekarsko-Dentystycznym w Zabrzu, Śląski Uniwersytet Medyczny w Katowicach
}

\section{Streszczenie}

Jod jest pierwiastkiem należącym do niezbędnych bioaktywnych składników diety, który ma udział w syntezie hormonów tarczycy, a te z kolei wpływają na prawidłowy rozwój i funkcjonowanie organizmu. W sytuacji gdy spożycie jodków jest mniejsze niż $50 \mu \mathrm{g} /$ dobę, gruczoł tarczowy nie jest w stanie utrzymać syntezy hormonów tarczycy na prawidłowym poziomie. Wyniki badań z lat 1992/1993 Polskiej Komisji ds. Kontroli Zaburzeń z Niedoboru Jodu były bezpośrednim powodem powrotu do obowiązkowego jodowania soli kuchennej. Sól kuchenna jest powszechnie stosowanym nośnikiem jodu. Zgodnie z zaleceniami Światowej Organizacji zdrowia dzienne spożycie soli nie powinno przekraczać 5 g NaCl (2 g $\mathrm{Na}$ ) na osobę. Kontrolowanie zawartości Na w diecie jest metodą prewencji chorób sercowo-naczyniowych. Prowadzone są równocześnie działania mające na celu zwiększenie spożycia innych naturalnych nośników jodu (mleko, woda mineralna). Alternatywnym źródłem jodu w diecie są między innymi: dorsz, mintaj, łosoś, jaja, otręby pszenne, brokuły, suche nasiona grochu i orzechy laskowe. Zasadna jest idea wdrożenia jodowania wody mineralnej i mleka, a także biofortyfikacji wybranych warzyw oraz podawania jodu trzodzie i bydłu w celu zapewnienia odpowiedniej jego podaży w związku z zaleceniami ograniczenia spożycia soli kuchennej.

Słowa kluczowe: jod, dieta, nadciśnienie tętnicze, jodowanie soli, amiodaron

Folia Cardiologica 2019; 14, 2: 156-160

\section{Wstęp}

Jod jest pierwiastkiem należącym do niezbędnych bioaktywnych składników diety, który ma udział w syntezie hormonów tarczycy, a te z kolei wpływają na prawidłowy rozwój i funkcjonowanie organizmu. Jest jednym z najsilniejszych antyoksydantów i wykazuje ochronne działanie w procesach zapalnych i nowotworowych [1].

Jod należy do składników odżywczych, które nie są magazynowane w organizmie człowieka i musi być dostarczany

Adres do korespondencji: prof. dr hab. n. med. Barbara Zubelewicz-Szkodzińska, Katedra Profilaktyki Chorób Metabolicznych, Wydział Zdrowia Publicznego w Bytomiu, Śląski Uniwersytet Medyczny w Katowicach, ul. Piekarska 18, 41-900 Bytom, tel. 323976541 , faks 323976532 , e-mail: basiazub@poczta.onet.pl 
z dietą. Niedostateczna podaż tego pierwiastka prowadzi do wystąpienia jego niedoborów, nadmiar zaś może wywoływać nadczynności tarczycy $[1,2]$.

\section{Zalecenia dietetyczne dotyczące podaży jodu}

Rekomendacje Światowej Organizacji Zdrowia (WHO, World Health Organization) co do optymalnego dziennego spożycia jodków są następujące: dla osób dorosłych - 150 g/ /dobę, dla kobiet w ciąży i podczas laktacji - $250 \mu \mathrm{g} /$ dobę, w pierwszym roku życia $50 \mu \mathrm{g} /$ dobę, w wieku od 1-5 lat - $90 \mu \mathrm{g} /$ dobę oraz w wieku 6-12 lat $-120 \mu \mathrm{g} /$ dobę [3]. W sytuacji gdy spożycie jodków jest mniejsze niż 50 mg/ /dobę, gruczoł tarczowy nie jest w stanie utrzymać syntezy hormonów tarczycy na prawidłowym poziomie. W następstwie czynnościowo przerasta i zmienia swoją strukture, co ostatecznie prowadzi do rozwoju niedoczynności tarczycy. Brak hamowania wydzielania hormonu tyreotropowego (TSH, thyroid-stimulating hormone) przez przysadkę mózgową dodatkowo potęuje przerost gruczołu (TSH jest także czynnikiem wzrostowym) [1].

Należy zatem dążyć do utrzymania prawidłowego spożycia jodu, ponieważ przede wszystkim jego niedobór (ale również - spotykane stosunkowo rzadko - nadmierne spożycie jodu) niekorzystnie wpływa na zdrowie populacji. Stosowanie profilaktyki jodowej powinno być stale monitorowane, aby oceniać jej efektywności, a także ustalać optymalne zaopatrzenie w jod [1, 4].

Polska Komisja ds. Kontroli Zaburzeń z Niedoboru Jodu (PCCIDD, Polish Council for Control of lodine Deficiency Disorders) zdecydowała o przeprowadzeniu badań epidemiologicznych w latach 1992-1993, obejmujących dzieci i młodzież szkolną, noworodki i kobiety w ciąży. Wyniki tych badań były bezpośrednim powodem powrotu do powszechnego, obowiązkowego jodowania soli kuchennej (20-40 mgKJ/kg) od 1997 roku [1, 2, 4]. Komisja określiła także pozostałe wskazania do prowadzenia profilaktyki: dodatkowe jodowanie żywienia wstępnego i następnego dla noworodków (10 $\mu \mathrm{g} / 100 \mathrm{ml}$ mleka) oraz dodatkowej suplementacji kobiet w ciąży i kobiet karmiących w dodatkową dawkę jodu 150-200 $\mu \mathrm{g} /$ dobę [1].

Model ten okazał się bardzo efektywny. Występowanie wola u dzieci szkolnych zmniejszyło się o $30-80 \%$ w porównaniu z latami 1992-1993; a u najmłodszej grupy (6-8 lat) występowało ono tylko u 2,6\% dzieci, czyli poniżej poziomu endemicznego [1]. Obserwowany wcześniej wzrost stężenia TSH u noworodków powyżej $20 \mu \mathrm{jm} . / \mathrm{ml}$ zmniejszył się z 2,0\% do 0,16\%, częstość występowania wola u kobiet w ciąży zmalała z $80 \%$ do $19 \%$, zmniejszyła się także częstość występowania zróżnicowanego raka tarczycy u kobiet [1].

W 2002 roku uznano polski model profilaktyki niedoborów jodu za efektywny i bezpieczny. Stwierdzono, że nie ma ryzyka populacyjnego niedoczynności tarczycy w przebiegu niedoboru jodu i nadwrażliwości w wyniku spożywania jodu $[1,3]$.

Należy jednak dodać, że nie udało się osiągnąć całkowitego sukcesu. U starszych dzieci (będących zwłaszcza w okresie dojrzewania) wole występuje nadal w 7-8\% w zależności od regionu, a częstość wydalania jodu z moczem powyżej $100 \mu \mathrm{g} / \mathrm{I}$ nie osiągnęła pożądanej wartości $50 \%$. Ciągle tylko $70 \%$ kobiet w ciąży otrzymuje zalecaną dawkę jodu i chociaż częstość występowania raka tarczycy u kobiet jest mniejsza, nadal jest 3-4-krotnie większa niż w okresach regularnego jodowania. Wreszcie jakość jodowania soli obejmuje 96\% zalecanych norm [1, 5].

Narodowy Program Eliminacji Zaburzeń w Przebiegu Niedoboru Jodu został przerwany w latach 2003-2005, ponowne powrócono do niego w roku 2006 i jest kontynuowany [1].

\section{Dieta z ograniczeniem soli w profilaktyce chorób układu sercowo-naczyniowego a podaż jodu}

Osobnym zagadnieniem jest prowadzenie profilaktyki jodowej i zalecane ograniczenie spożycia soli do $5 \mathrm{~g} /$ dobę. Sól kuchenna jest bowiem powszechnie stosowanym nośnikiem jodu.

Zalecenia opracowane przez Światową Organizację Zdrowia (WHO, World Health Organization) (Paryż 2006, Luksemburg 2007) wynikają z udokumentowanej roli soli w zwiększeniu ryzyka chorób układu sercowo-naczyniowego, w tym: nadciśnienia tętniczego, miażdżycy, udarów i zawałów serca oraz niektórych chorób nowotworowych. Zgodnie z zaleceniami WHO dzienne spożycie soli nie powinno przekraczać $5 \mathrm{~g} \mathrm{NaCl}$ (2 g Na) na osobę [6]. Średnie dzienne spożycie soli w Polsce wynosi 13,5 g/osobe, w tym 8,8 g soli kuchennej, a w niektórych regionach kraju dochodzi do 15,0 g/osobe [4].

Według Standardów Postępowania Dietetycznego w Kardiologii - stanowiska Polskiego Towarzystwa Dietetyki z 2016 roku - wcześniejsze lata obfitowały w ponad milion zgonów powiązanych ze spożyciem $\mathrm{NaCl}$ w ilości przekraczających $5 \mathrm{~g} /$ dobę rekomendowanych przez WHO (1,65 mln zgonów w 2010 r.) [7].

Raport opracowany przez Światową Federację Serca (WHF, World Heart Federation), Europejskie Towarzystwo Nadciśnienia Tętniczego (ESH, European Society of Hypertension) oraz Europejskie Stowarzyszenie Zdrowia Publicznego (EUPHA, European Public Health Association) dotyczące wpływu spożycia sodu na występowanie chorób układu krążenia w krajach o niskim i średnim poziomie produktu krajowego brutto dowodzi, że zmniejszenie spożycia sodu 0 1,76 g/dobę/osobę przyczynia się do obniżenia ciśnienia tętniczego o 3,39/1,54 mm Hg [7, 8]. Kontrolowanie zawartości Na w diecie jest więc metodą prewencji chorób 
sercowo-naczyniowych ze szczególnym uwzględnieniem wystąpienia nadciśnienia tętniczego, natomiast w przypadku osób, które chorują na nadciśnienie tętnicze, znacząco wpływa na obniżenie podwyższonych wartości [9].

Zgodnie z wytycznymi Polskiego Towarzystwa Nadciśnienia Tętniczego (PTNT) z 2015 roku dieta bogata $w \mathrm{NaCl}$ może być przyczyną wystąpienia trudności w leczeniu nadciśnienia tętniczego, w związku z tym u chorych należy zwracać szczególną uwagę na ograniczenie soli kuchennej poniżej 5,0 g/dobę [8]. Uważa się, że efekt hipotensyjny redukcji zawartości Na w diecie u osób starszych, „sodowrażliwych", z rozpoznaną cukrzycą, zespołem metabolicznym oraz przewlekłą niewydolnością nerek jest zdecydowanie większy i może skutkować ograniczeniem liczby i dawek leków stosowanych przez tych pacjentów [8].

Kypridemos i wsp. [10] zastosowali model mikrosymulacyjny do oceny wpływu prowadzonych działań w zakresie ograniczenia spożycia NaCl w Wielkiej Brytanii na profilaktykę chorób sercowo-naczyniowych. Wprowadzenie polityki zmniejszenia spożycia NaCl w latach 2003-2015 spowodowało zapobieżenie lub opóźnienie wystąpienia chorób sercowo-naczyniowych u 52000 osób, jednocześnie zapobiegło 10000 zgonom z przyczyn sercowo-naczyniowych [10].

Wobec przedstawionych opinii ważne jest, aby znaleźć „złoty środek” między podażą jodu zabezpieczająca prawidłową funkcję tarczycy a ograniczeniem spożycia soli kuchennej zalecanym przez towarzystwa kardiologiczne. Należy przy tym pamiętać, że sól kuchenna jest głównym dostarczycielem jodu w codziennej diecie [10].

Opracowane przez grono ekspertów Instytutu Żywności i Żywienia „Stanowisko w sprawie podjęcia inicjatywy zmniejszenia spożycia soli w Polsce" określa kierunki działania obejmujące zmiany receptur przetworów spożywczych w przemyśle spożywczym i placówkach żywienia zbiorowego, wzmożenie nadzoru organów urzędowej kontroli żywności, kontynuacje odpowiednich działań legislacyjnych [7]. Dotyczą one również działań edukacyjnych skierowanych do różnych grup: konsumentów, producentów, pracowników ochrony zdrowia i instytucji zdrowia publicznego oraz innych grup mających wpływ na nasz styl życia. Ważne w kształtowaniu tych zaleceń jest także Stanowisko PTNT zmierzające do ograniczenia spożycia soli przez działania profilaktyczne i promocyjne [11]. Wymaga to jednak ścisłej współpracy z PCCIDD w zakresie niezbędnych modyfikacji systemu profilaktyki jodowej [8].

Autorom programu zarzucono, że w profilaktyce jodowej jako nośnik jodu zastosowali mało pożądaną substancję - chlorek sodu, przeciwwskazany w nadciśnieniu tętniczym i innych chorobach układu sercowo-naczyniowego. Tymczasem w Polsce spożycie chlorku sodu było i jest nadal nadmierne, jeszcze kilka lat temu norma spożycia wyznaczona przez WHO była przekroczona 3-krotnie [2].
Jak już wspomniano, obecnie spożycie soli w naszym kraju znacznie przekracza dzienną normę spożycia, konieczne jest zatem poszukiwanie innych alternatywnych źródeł jodu, które zabezpieczyłyby jego dzienne zapotrzebowanie. Endokrynolodzy zgadzają się z kardiologami, że nie należy nikogo zachęcać do spożywania soli. Jednak jednocześnie obawiają się, że dalszy spadek spożycia soli jodowanej niekorzystnie odbije się na profilaktyce jodowej i epidemiologii chorób tarczycy. Przeciętna zawartość jodu w 100 g soli kuchennej jodowanej wynosi $2293 \mu$ g [12]. Aby z soli dostarczyć wymagane $150 \mu$ g dziennego zapotrzebowania w jod, należy spożyć 6,5 g samej soli jodowanej, co przekracza zalecane 5,0 g według WHO [13]. Taka sytuacja wymusza więc zastosowanie innych rozwiązań, które godzić będą zalecenia kardiologów z założeniami profilaktyki jodowej promowanych przez endokrynologów. Może nim być na przykład dopuszczenie dodatkowo do jodowania produktów spożywczych zawierających jodan potasu $\left(\mathrm{KIO}_{3}\right)$ [2].

Prowadzone są działania mające na celu zwiększenie spożycia innych naturalnych nośników jodu (mleko, woda mineralna) [14]. Rozważa się także możliwości zwiększenia zawartości jodu w wybranych warzywach za pomocą ich biofortyfikacji [15]. Innym działaniem jest wprowadzenie jodu do łańcuchów pokarmowych przez podawanie go trzodzie i bydłu.

\section{Leki a podaż jodu}

Omawiając podaż jodu, nie można nie wspomnieć o lekach i środkach kontrastowych zawierających jod. Farmakologiczne dawki jodu (mogące przekraczać wielokrotnie dobowe zapotrzebowanie) są zawarte w wielu substancjach stosowanych w diagnostyce i leczeniu. Zalicza się do nich na przykład radiologiczne środki cieniujące (zawierające 140-400 mg w $1 \mathrm{ml}$ ), środki odkażające (jodopowidon - 10 mg jodu w 1 ml), mocny płyn Lugola (127 mg jodu w $1 \mathrm{ml}$, czyli ok. 20 kropli) [16]. Również niektóre leki antyarytmiczne, skądinąd bardzo skuteczne - zwłaszcza amiodaron - mogą indukować zaburzenia funkcji tarczycy przez dużą zawartość jodu (1 tabl. amiodaronu w dawce 200 mg zawiera ok. 75 mg jodu). Dawkowanie leku ze wskazań kardiologicznych zakłada przyjmowanie nawet kilku tabletek dziennie, a to znacznie przekracza dobowe zapotrzebowanie organizmu na jod [1]. Ponadto lek kumuluje się w tkance tłuszczowej i mięśniowej, a ze względu na długi okres półtrwania (ok. 100 dni), uwalnianie jodu odbywa się także po odstawieniu preparatu [16].

Amiodaron ma wielokierunkowy wpływ na metabolizm hormonów tarczycy. Jego cząsteczka wykazuje podobieństwo do cząsteczki T4 i być może współzawodniczy z T4 o wiązanie z odpowiednim receptorem; lek hamuje monodejodynację obwodową T4 do T3 oraz indukuje procesy 
Tabela 1. Zawartość jodu w wybranych produktach spożywczych (na podstawie [12])

\begin{tabular}{|c|c|}
\hline Nazwa produktu & $\begin{array}{c}\text { Zawartość jodu } \\
{[\mu \mathrm{g} / 100 \mathrm{~g} \text { produktu] }}\end{array}$ \\
\hline \multicolumn{2}{|l|}{ Ryby } \\
\hline Dorsz świeży & 110 \\
\hline Mintaj świeży & 103 \\
\hline Łosoś świeży & 44 \\
\hline Makrela wędzona & 40 \\
\hline Śledź solony/śledź wędzony & 30 \\
\hline Śledź świeży & 24,3 \\
\hline Tuńczyk w oleju & 25 \\
\hline Flądra świeża & 20 \\
\hline Pstrąg tęczowy świeży & 13 \\
\hline Szczupak świeży & 8 \\
\hline \multicolumn{2}{|l|}{ Mleko i jego przetwory } \\
\hline Ser rokpol tłusty & 40 \\
\hline Ser edamski tłusty & 30 \\
\hline Ser brie tłusty & 11,2 \\
\hline Kefir $2 \%$ tłuszczu & 7,5 \\
\hline Ser topiony edamski & 7,1 \\
\hline Maślanka 0,5\% tłuszczu & 5,9 \\
\hline \multicolumn{2}{|l|}{ Jaja } \\
\hline Jaja kurze, całe & 9,5 \\
\hline Białko jaja kurzego & 6,8 \\
\hline Żółtko jaja kurzego & 12 \\
\hline \multicolumn{2}{|l|}{ Produkty zbożowe } \\
\hline Otręby pszenne & 31 \\
\hline Płatki owsiane & 5,9 \\
\hline Płatki żytnie & 5,7 \\
\hline \multicolumn{2}{|l|}{ Warzywa } \\
\hline Brokuły & 15 \\
\hline Groch (suche nasiona) & 13,9 \\
\hline Szpinak & 12 \\
\hline Rzodkiewka & 8 \\
\hline Soja (nasiona suche) & 6,3 \\
\hline Bób & 6 \\
\hline \multicolumn{2}{|l|}{ Orzechy } \\
\hline Laskowe & 17 \\
\hline Arachidowe & 13 \\
\hline Włoskie & 9 \\
\hline \multicolumn{2}{|l|}{ Inne } \\
\hline Sól biała, jodowana & 2293 \\
\hline $\begin{array}{l}\text { Jodowana woda mineralna } \\
\text { 'Ustronianka' }\end{array}$ & $150 \mu \mathrm{g} / \mathrm{l}$ \\
\hline
\end{tabular}

immunologiczne w tarczycy [16]. Może wywoływać zarówno niedoczynność tarczycy (rzadziej), jak i nadczynność tarczycy (częściej). 0 ile niedoczynność zdarza się zwykle już w trakcie przyjmowania amiodaronu, o tyle czas wystąpienia nadczynności bywa różny; może ona bowiem objawić się nawet po kilku miesiącach od zaprzestania przyjmowania leku [17]. Środki cieniujące i amiodaron mogą wywoływać tyreotoksykoze w przebiegu destrukcyjnego zapalenia tarczycy [18].

\section{Źródła jodu w diecie}

Niewiele jest znanych, tak skutecznych interwencji w zakresie profilaktyki zdrowotnej jak program profilaktyki niedoboru jodu realizowany w Polsce od wielu lat $[1,13]$. Jak opisano, korzyści zdrowotnych programu jest bardzo wiele i dotyczą one nie tylko prawidłowej funkcji dokrewnej gruczołu tarczowego, profilaktyki wrodzonej niedoczynności tarczycy, zmniejszenia śmiertelności okołoporodowej noworodków, ale także rozwoju nowotworu złośliwego [19].

Wobec współistnienia zaleceń będących odpowiedzią na coraz częstsze występowanie chorób układu krążenia, a dotyczących ograniczenia podaży soli, należy szukać alternatywnych źródeł jodu, które zapewniłyby prawidłową jego podaż i pokryły dzienne zapotrzebowanie. W tabeli 1 przedstawiono źródła jodu w diecie [12].

Zalecając więc pacjentom dietę z ograniczeniem soli kuchennej, można zaproponować alternatywne źródła jodu pod postacią innych produktów spożywczych, godząc w ten sposób na pierwszy rzut oka niedające się pogodzić zalecenia towarzystw naukowych.

\section{Wnioski}

Ze względu na podkreślaną przez lekarzy endokrynologów konieczność podaży jodu w celu prewencji zaburzeń funkcjonowania gruczołu tarczowego, a także zalecenie lekarzy kardiologów ograniczenia spożycia jodowanej soli kuchennej w związku ze zwiększonym ryzykiem chorób układu sercowo-naczyniowego, w szczególności nadciśnienia tętniczego, należy podjąć alternatywne działania dostarczenia jodu do organizmu. W tej sytuacji zasadna jest idea wdrożenia jodowania wody mineralnej i mleka, a także biofortyfikacji wybranych warzyw oraz podawania jodu trzodzie i bydłu. Warto również pamiętać o produktach spożywczych, które są źródłem jodu, aby konsekwentnie umieszczać je w codziennym jadłospisie.

\section{Konflikt interesów}

Autorzy deklarują brak konfliktu interesów. 


\section{Abstract}

lodine is one of the essential bioactive components of a diet and which has an influence on the thyroid hormones synthesis, and these hormones affect the proper development and functioning of the organism. In the situation when the iodides consumption is less than $50 \mu \mathrm{g} /$ day, it is unable to maintain the thyroid hormones synthesis at a normal level by the thyroid gland. The 1992/1993 Polish Council for Control of lodine Deficiency Disorders study results were a direct reason for the compulsory resumption of table salt iodination. Table salt is a, commonly used, iodine carrier. According to the World Health Organization recommendations, the daily salt intake should not exceed $5 \mathrm{~g} \mathrm{NaCl}(2 \mathrm{~g} \mathrm{Na})$ per person. Verification of $\mathrm{Na}$ content in the diet is a method for cardiovascular diseases prevention. Actions aimed at increasing of the other natural iodine carriers (milk, mineral water) intake are taken. Alternative sources of iodine in the diet are include: codfish, pollock, salmon, eggs, wheat bran, broccoli, dried pea seeds and hazelnuts. Iodination of mineral water and milk, as well as biofortification of the selected vegetables and feeding flock and cattle by food rich in iodine should be concerned according to salt restriction diet.

Key words: iodine, diet, hypertension, salt iodination, amiodarone

Folia Cardiologica 2019; 14, 2: 156-160

\section{Piśmiennictwo}

1. Szybiński Z. Polish Council for Control of lodine Deficiency Disorders. Work of the Polish Council for Control of lodine Deficiency Disorders, and the model of iodine prophylaxis in Poland. Endokrynol Pol. 2012; 63(2): 156-160, indexed in Pubmed: 22538756.

2. Włodarek D, Lange E, Kozłowska L, Głąbska D. Dietoterapia. Składniki mineralne. PZWL, Warszawa 2014: 164.

3. Gietka-Czernel M. Profilaktyka niedoboru jodu. Post Nauk Med. 2015; 28(12): 839-845.

4. Szybiński Z, Jarosz M, Hubalewska-Dydejczyk A, et al. [lodine-deficiency prophylaxis and the restriction of salt consumption - a $21^{\text {st }}$ century challenge]. Endokrynol Pol. 2010; 61 Suppl 1(1): 1-6, indexed in Pubmed: 22127630.

5. Gołkowski F. Zaburzenia z niedoboru jodu. Trendy w Endokrynologii. 2012; 2(2): 3-8.

6. Traczyk I, Jarosz M. Spożycie soli - zalecenia i programy WHO oraz UE. Przem Spoż. 2011; 65(5): 18-21.

7. Gajewska D, Pałkowska-Goździk E, Lange E, et al. Standardy postępowania dietetycznego w kardiologii. Stanowisko PTD 2016 Dietetyka. 2016; 9: 16-17.

8. Tykarski A, Narkiewicz K, Gaciong Z, et al. Zasady postępowania w nadciśnieniu tętniczym - 2015 rok. Nadciśnienie Tętnicze w Praktyce. 2015; 1(1): 1-70.

9. Narula J, Mancia G, McKee M. Salt intake and Cardiovascular Disease. Eur Heart J. 2017; 38(10): 697-699, doi: 10.1093/eurheartj/ehx057, indexed in Pubmed: 28938723.

10. Kypridemos C, Guzman-Castillo M, Hyseni L, et al. Estimated reductions in cardiovascular and gastric cancer disease burden through salt policies in England: an IMPACTNCD microsimulation study. BMJ
Open. 2017; 7(1): e013791, doi: 10.1136/bmjopen-2016-013791, indexed in Pubmed: 28119387.

11. Tykarski A, Widecka K, Filipiak KJ. Zasady postępowania w nadciśnieniu tętniczym - 2015 rok. Wytyczne Polskiego Towarzystwa Nadciśnienia Tętniczego. Próba komentarza na temat zmian i ich zasadności. Nadciśnienie Tętnicze w Praktyce. 2015; 2: 71-94.

12. Kunachowicz H, Nadolna I, Przygoda B, et al. Wartość odżywcza wybranych produktów spożywczych i typowych potraw. Wydanie V rozszerzone. PZWL 2009: 114-117.

13. Dudzik I. Mądry Polak po jodzie. Medical Tribune. https://podyplomie. pl/medical-tribune/25066,madry-polak-po-jodzie 2017 (3.10.2018).

14. Szybiński Z. Sytuacja profilaktyki jodowej w Polsce w świetle ostatnich rekomendacji WHO. dotyczących ograniczenia spożycia soli. Pediatric Endocrinology, Diabetology and Metabolism. 2009; 15(2): 103-107.

15. Strzetelski P. Warzywa biofortyfikowane jodem. Hasło Ogrodnicze. 2015; 6: 10-12.

16. Żach M, Kryjan K, Ambroziak U, et al. Nadczynność tarczycy po podaniu środków cieniujących zawierających jod. Kardiol Pol. 2013; 71(7): 752-756, doi: 10.5603/kp.2013.0166.

17. Jabrocka-Hybel A, Bednarczuk T, Bartalena L, et al. Amiodarone and the thyroid. Endokrynol Pol. 2015; 66(2): 176-186, doi: 10.5603/ /EP.2015.0025, indexed in Pubmed: 25931048.

18. Eskes SA, Wiersinga WM. Amiodarone and thyroid. Best Pract Res Clin Endocrinol Metab. 2009; 23(6): 735-751, doi: 10.1016/j. beem.2009.07.001, indexed in Pubmed: 19942150.

19. Karwowska R. Niedoczynność tarczycy u dzieci. Pediatr Med Rodz. 2017; 13(4): 479-490. 